\title{
Abstract \\ Comparative Analysis of CVE Policies between Canada, US, UK, Sweden, and North Macedonia ${ }^{\dagger}$
}

\author{
Alberto Montrond \\ Community Safety Branch, Emergency Preparedness Research Evaluation \& Practice (EPREP) Program, \\ Harvard T.H. Chan School of Public Health, 90 Smith Street, Boston, MA 02115, USA; \\ amontrond@hsph.harvard.edu \\ + Presented at the Global Safety Evaluation Workshop, Online, 1 July-31 December 2020.
}

check for updates

Citation: Montrond, A. Comparative Analysis of CVE Policies between Canada, US, UK, Sweden, and North Macedonia . Proceedings 2021, 77, 6. https://doi.org/10.3390/ proceedings 2021077006

Published: 25 April 2021

Publisher's Note: MDPI stays neutral with regard to jurisdictional claims in published maps and institutional affiliations.

Copyright: (C) 2021 by the author. Licensee MDPI, Basel, Switzerland. This article is an open access article distributed under the terms and conditions of the Creative Commons Attribution (CC BY) license (https:// creativecommons.org/licenses/by/ $4.0 /)$.
Abstract: In the field of counter-terrorism (CT) and countering violent extremism (CVE), policymakers are in constant need of accurate data to make informed decisions to support existing programs and develop new approaches to prevent radicalization to violence. The goal of the comparative analysis in this presentation is to identify the types of data needed to assess the impact of CT and CVE programs based on each country's policy goals. A comparative analysis of the five countries' specific CT/CVE policies was conducted to identify common themes and data needs. The first most widely discussed theme is the need to maintain and expand collaborations and information sharing across countries-all five policies strongly emphasize the importance of such collaborative efforts. All policies address the need for strengthening collaborations at the local level, considering the important role civil society plays in the frontline response to violent extremism. In particular, the North Macedonian policy recognizes the need to fully engage in multidisciplinary interagency efforts that include civil society in the process for reconciliation of ethnic and cultural divides, educate and promote democratic values in schools and faith based communities. According to the policy documents, it can be found that there is a need for a better understanding of what types of collaborative efforts and partnerships are needed to establish effective CT and CVE programs. All policies stress the need to address a range of extremist ideologies including Jihadist, Far Left, and Far Right groups to address radicalization in the online space as well as through in-person interventions. In terms of interventions, there is a need to understand what type of training is most effective to equip frontline professionals with the knowledge and skills to intervene when individuals engaged in VE come to their attention. The United States policy is innovative with respect to the others because it introduces the concept of targeted violence. By doing so, it recognizes the importance of including situations where ideology is not a motivating factor or the motivations are unknown behind the acts of violence. The Swedish policy is distinguished by its detailed legislation supporting the prevention of terrorist acts. The UK policy emphasizes the need to contrast ideologies and views that are not aligned with UK values. All policies recognize the need for evidence on strategic efficacy and recognize the fact that programs and policies have been widely implemented without scientific proof of their effectiveness. In particular, the Canadian policy points to the need for identifying best practices that can be transferred from case to case or country to country. As an area of policy improvement across countries, there is certainly a lack of clarity on the roles and responsibilities of the many agencies that may be potentially involved in prevention efforts, still leaving a nebulous space in terms of when and how security intercepts social work and public health.

Keywords: counterterrorism; countering violent extremism; policy analysis; qualitative analysis

Institutional Review Board Statement: Not applicable.

Informed Consent Statement: Not applicable.

Data Availability Statement: Not applicable. 